\title{
Medicinal and Aromatic Plants Value Chain Performance in Albania: Information System Implementation
}

Julian Lekoçaj

Department of Forestry, Faculty of Forestry, Agricultural University of Tirana,

Albania

Valter Hoxha

Department of Economics, Faculty of Economy, Mediterranean University of

Albania, Albania

\section{Abstract}

The medicinal and aromatic plants (MAPs) represent a very important sector for the Albanian economy. According the COMTRADE 2018 statistics, this sector exports rank the country at the 16-th position in the World, indicating that Albania has a very big economical potential in this area (Hoxha, 2016, Naka et al., 2003). Despite this potential, the last 20 years records show that these exports have remained almost constant. The lack of information about the value chain, indicating the asymmetric information is the main reasons of this performance (USAID, 2010, Lekocaj et al, 2017). Therefore, conclusion emerges that there is a limited rationality between the economic agents who work and study in this sector. This study object is to identify the information sources and to fabricate all the channels where this information goes through. To achieve our objectives, we are using systemic approach. At the national level, we have chosen 3 municipalities, while for the information level regarding this sector's actors we have chosen 12 exporting companies, the most important ones in Albania. The results show that the sector information system has methodological problems on their identification and a lack of a central database, which can be updated at any moment with new information in time and space from all the value chain actors.

Keywords: Medicinal and aromatic plants, performance, limited rationality, systematic method, information system

JEL classification: $032, \mathrm{D} 82,013$

\section{Introduction}

Albania because of its geographic position has a variety of medicinal and aromatic plants (MAPs). The complete inventory realized in 1987 from the government institutions shows that the Albanian territory has a capacity of around 213,000 tons (Llubani, 1988; Hoxha, 2016). In the Albanian economy, the MAPs represent a very important sector. According the last COMTRADE 2018 statistics, this sector exports rank the country at the 16-th position in the World with an amount of 7277 tons (Figure 1). The country has lost two positions in compare with 2014 (llbert et al., 2016). Figure 1 indicates the ranking of Albania among the best countries in the World for the MAPs exports in the end of 2017. 
Figure 1

The Ranking of Albania among the Best Countries in the World for the Maps Exports in the End of 2017



Source: Authors' illustration from COMTRADE database (2018)

At the national level, according to some studies, this sector employs between 70000 and 100000 low-income farmers who live in the marginalized hilly and mountainous areas (Naka et al., 2003; USAID, 2010) contributing to a large portion of income of their households (Paul, 2014). In monetary value, the MAPs sector is a very important voice in the payments balance sheet. In 2017, this export amounted to about $\$ 17$ million or about 16\% of total agricultural exports (Lekocaj et al., 2017).

Despite this sector importance, the statistics show that the exports profits have doubly decreased in compare with the communist era. In the communist era, exports of MAPs earned close to $\$ 50$ million (Paul, 2014). However, these exports, for the period 1996-2017, have dropped to an average of 16 million/year (Figure 2). On the other side, the annual growth rate of imports for MAPs in the world, compared with a base year (1988), have increased $8 \%$ in volume and $11 \%$ in value for the period 1988-2014 (llbert et al., 2016).

Economic theories give different explanations and reasoning for the market's problem and performance. They can derive from the market structure or from the sector operation mode, or from the company strategies that are directly linked with the available information by their administrators. So the lack of information or the asymmetric information makes that the economic agents will have a limited rationality toward their decision. Neo-Keynesian theory emphasizes that markets are inefficient due to the lack of transparency. Economic agents have limited rationality because of the asymmetric information. The asymmetry of this information leads agents to the selection of unsatisfactory products such as Insurance Contracts published by Rothschild and Stiglitz (1970). 
Figure 2

The Evolution of the MAPs Albanian Exports, Period 1996-2017

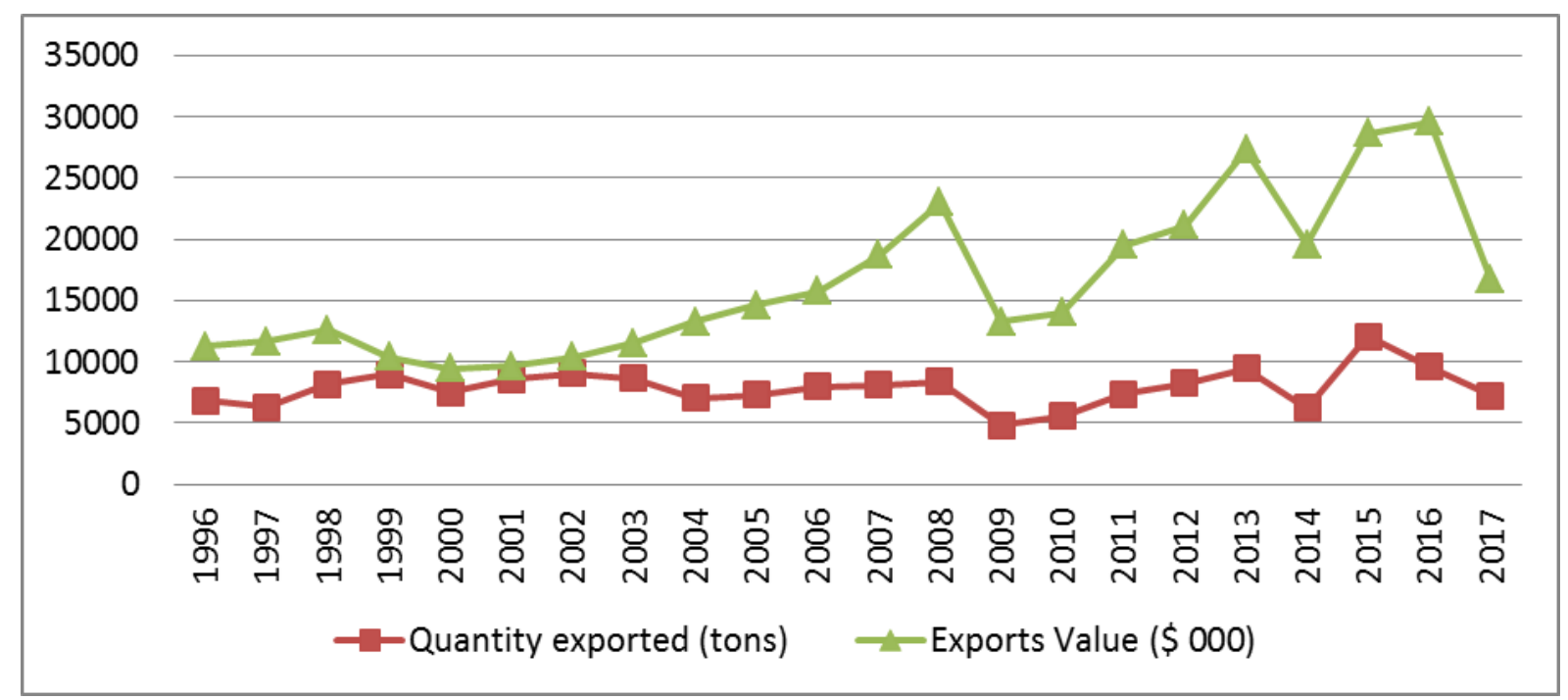

Source: Authors' illustration from COMTRADE database (2018)

In the Albanian MAPs sector case, the lack of information problem is identified by many studies. According to USAID study in 2010, "The Albanian statistics are not very reliable and it does not appear possible to obtain detailed data on export by type of MAP. So data provided by INSTAT are only at aggregated level, and it is not possible to obtain reliable data at product level (i.e. sage)", this information is not reliable (USAID, 2010: p. 1). In 2015 another study done by the French Agricultural Ministry MAPs sector also identifies the lack of information through all the value chain links (Hoxha, 2016). Also the last study done in 2018 by the authors Lekocaj et al. (2018), confirms the Stiglitz and Rothschild hypothesis where the value chain actors because of the lack of information had the trend to be directed toward a less qualitative product, what in the MAPs case would be the cultivated products (Lekocaj et al., 2018).

Seen in this context, this study proposes to deeper analyze the information system of the MAPs sector in Albania. The idea is to know the fabrication and the information channeling of the MAPs sector.

\section{Methodology}

To achieve our objectives, we use a systemic approach. This method gives us the opportunity to see in total the links between the elements that produce and offer the information. Through this method, we want to identify the main sources of the information production and the reason why this information is not complete and accurate. We classified the main sources of the information into 5 levels (figure 3). For the first level, we searched about the information, which can be found through the international organizations database like Eurostat, UN Comtrade, or even from the countries that import MAPs from Albania. 
Figure 3

The Information System Scheme for the Maps Value Chain in Albania

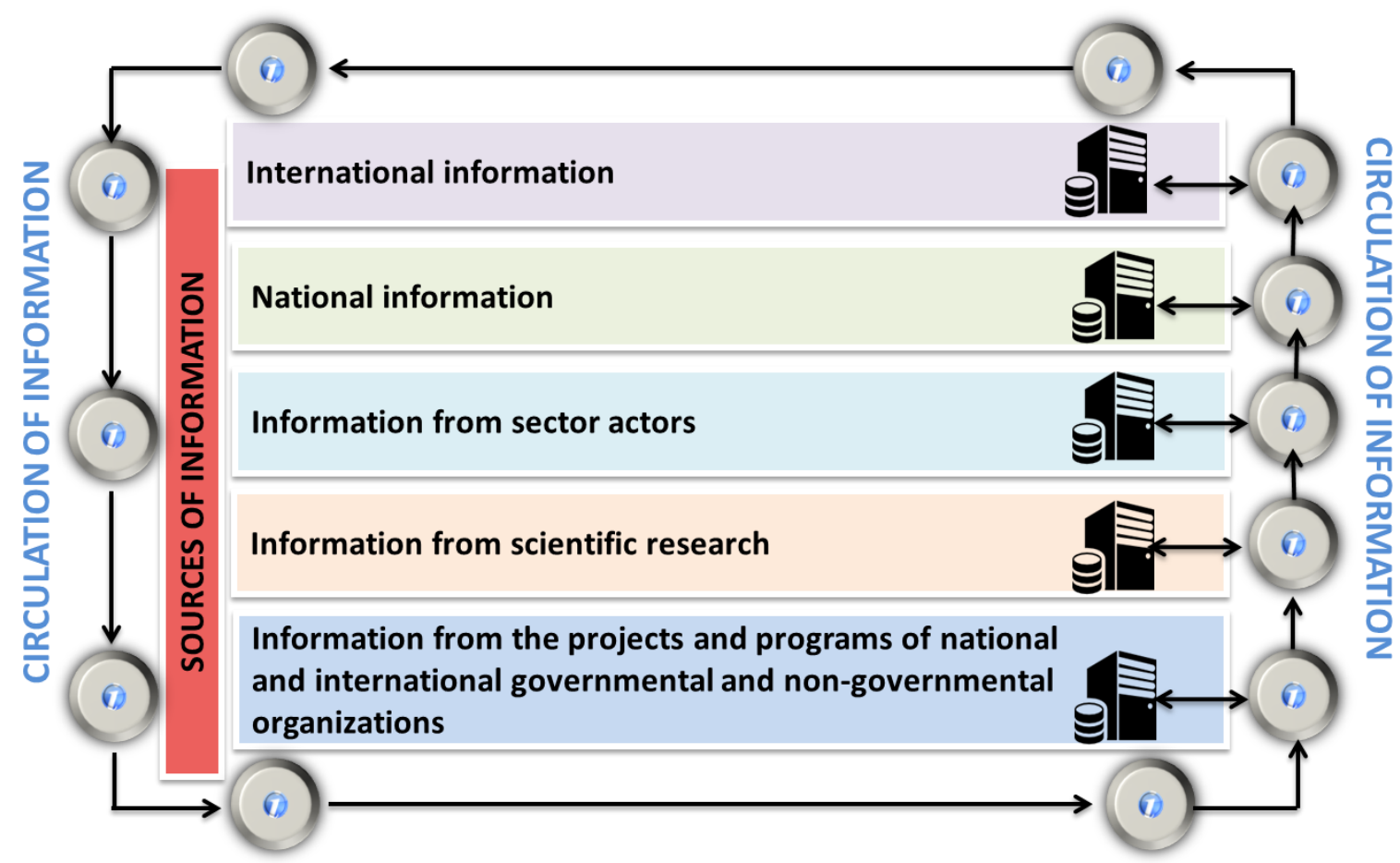

Source: Authors' illustration

For the second level, we searched the information that is offered by the government institutions database, such as Ministries, the statistics institution in center and the municipalities in localities. For that, we chose three regions that have an old tradition and great engagement in this sector and geographically represent three big parts of the Albanian territory (Figure 4). For south part was chosen Vlora, for the north part Shkodra and Malesia e Madhe, for the east central part Dibra. For every region, we chose the number of actors that would be interviewed. Therefore, for the MAPs fund administration we went to each of the respective municipalities.

For the third level, we searched about the information that is offered by the value chain actors. In defining the surveyed actors, we were based on the value chain approach. This method is widely used for the Value Chain Analysis (VCA) or for the asset's general theory (Kaplinsky et al., 2001) and by many international organizations for the agro-food value chain analysis. In the beginning, we identified the main actors of every value chain's link. For the exporters' link, we choose to interview most potential ones, (who are actually piloting the MAPs value chain) in order that our records could be as reliable as possible (figure 5). As below, in the figure 5 we have featured the main exporters for period 2015-2016 by ranking them according to the USAID study realized in 2010. Between them, we chose five leading companies as: Gjedra Company, Filipi Company, Elba Shehu Company, Mucaj and Xherdo Company. For the MAPs harvesters we decided to interview 30 (thirty) people for each region. 
Figure 4

Areas of Study

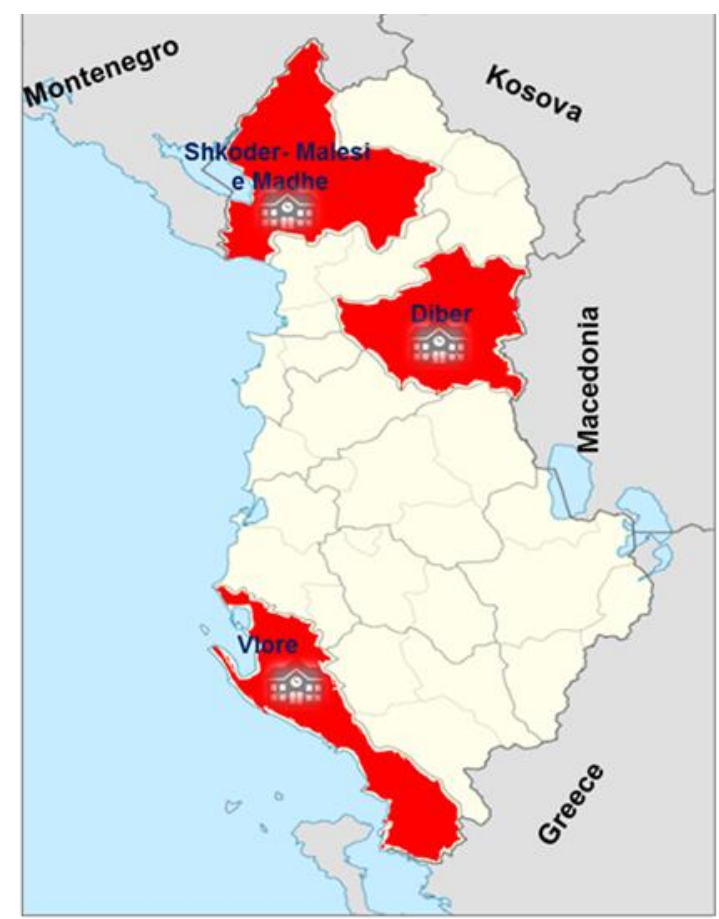

Source: Authors' illustration
Figure 5

Interviewed Actors

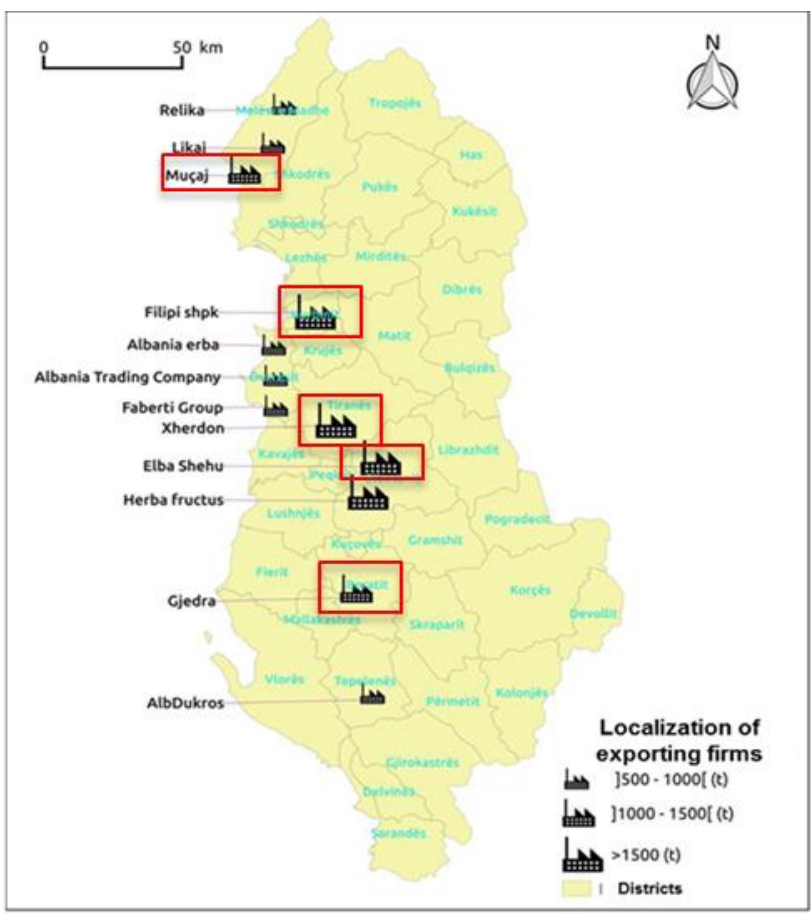

Source: Hoxha (2016)

For the forth level, we searched for the information that is offered by the researching institutions databases in Albania. For the last level, we put the information produced by other studies realized from national and international organizations (on a nongovernmental organizations level).

\section{Results}

Based on our research we thought to map the main actors where is produced and manufactured the information of MAPs value chain (figure 5). In this figure are shown the information channels between the actors that work and are interested about the MAPs exploitation, protection and management.

The results taken from our research show that there exist two types of actors that take place setting up and developing the MAPs value chain system information in Albania.

One group offers factual data based on the value chain actors activity, which are the directly actors and the institutions that register these statistics. In the other group, we have the actors that try through the scientific research and different projects to improve this information contributing on the methodological improvement and the information infrastructure. 
Figure 5

The Maps Value Chain Information Sources and its Circulation in Albania

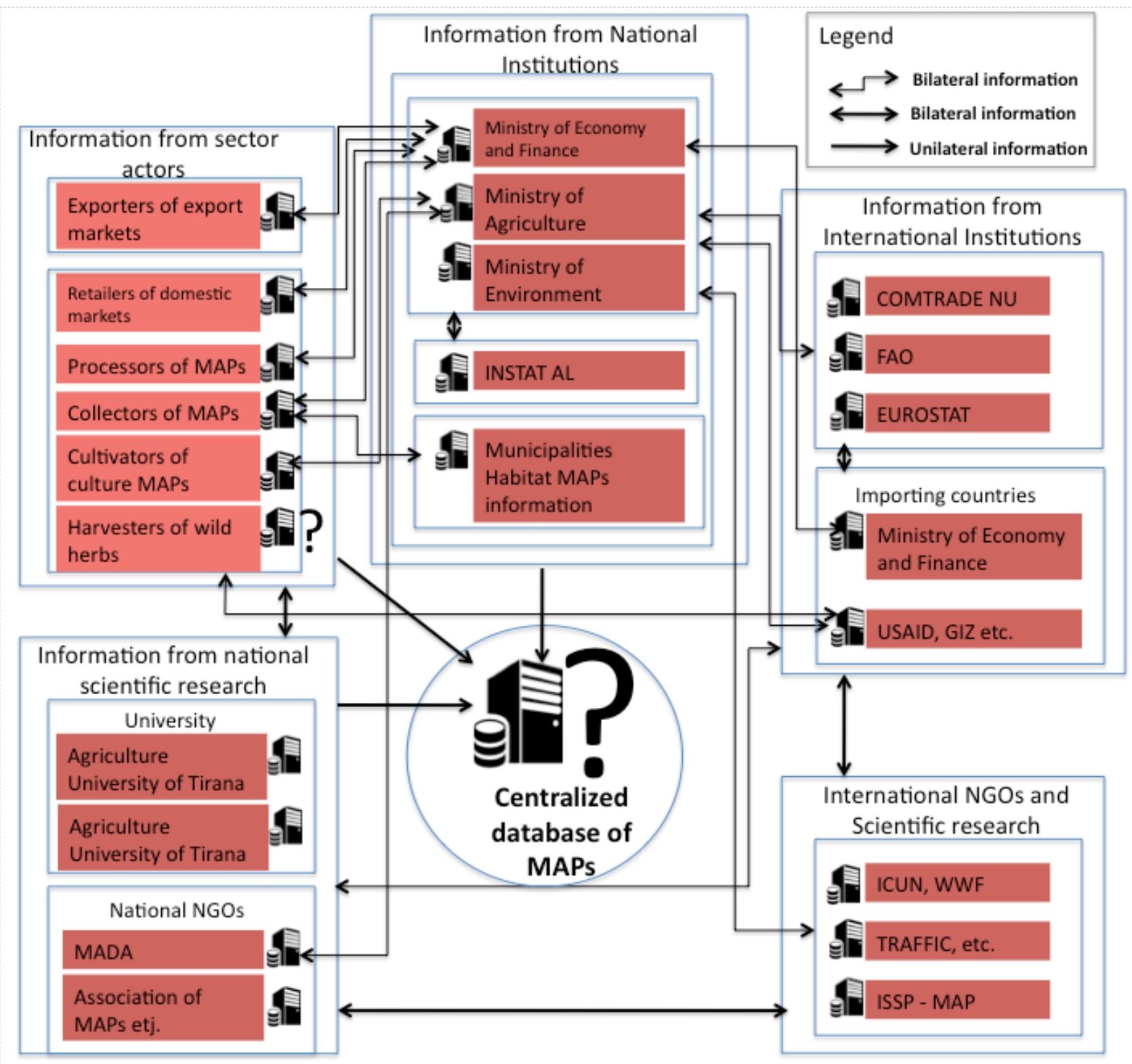

Source: Authors' illustration

In the first group, in the international institutions level, the main organizations that offer information about the MAPs sector in Albania are the United Nations (UN) database statistics such as COMTRADE and EUROSTAT. As shown in figure 6, the COMTRADE database except some plants, offers information in quantity and value for the MAPs group (HS1211) in a general level.

Figure 6 
The Albanian Maps Data from the UN COMTRADE Database (Commodity HS1211)

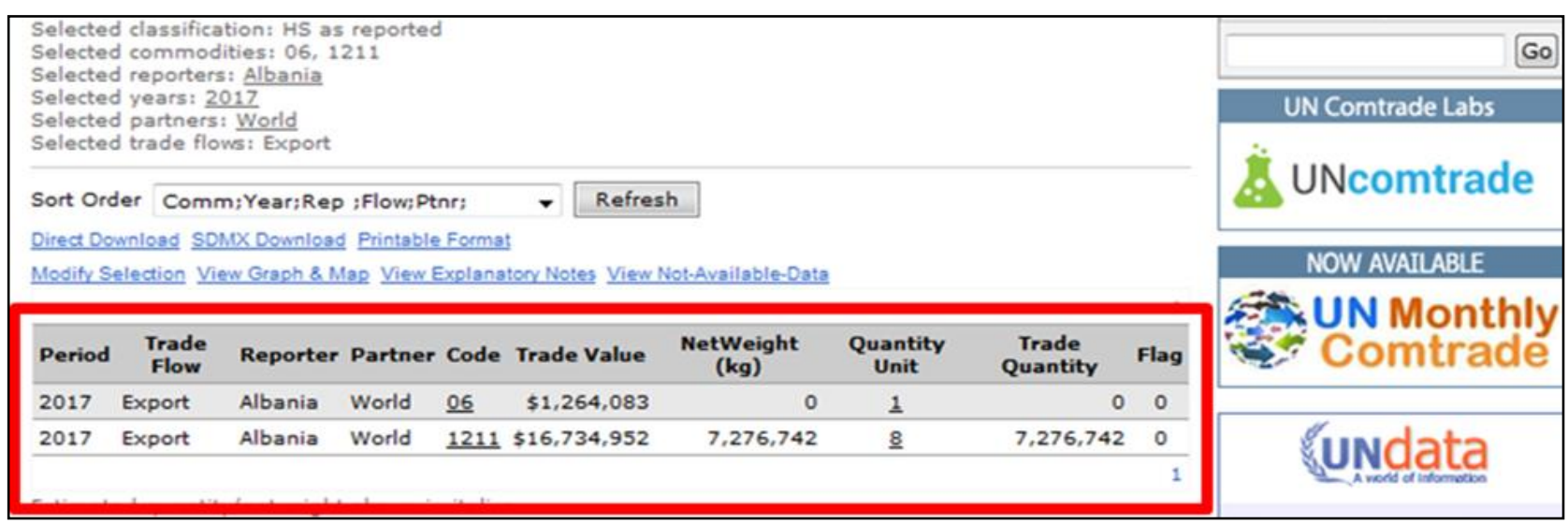

Source: Authors' illustration (2018)

These data can be found also from the customs of the importing countries that Albania does this trade (Figure 7). These data are in an aggregate or in a generalized level. Figure 7 shows the import-export data between France and Albania, taken by the French Customs, which are the same as those of COMTRADE database.

Figure 7

The Albanian MAPs Data from the French Customs Database

\begin{tabular}{|l|c|l|l|l|l|r|r|}
\hline Comtrade 2015 & 2014 & Import & 3301 & France & Albanie & 217233 & 3525 \\
\hline & & & & & & Euro & 0 \\
\hline DOUANE FR 2015 & 2012 & Export & 1211 & France & Albanie & 0 & 0 \\
\hline DOUANE FR 2015 & 2013 & Export & 1211 & France & Albanie & 1485 & 750 \\
\hline DOUANE FR 2015 & 2014 & Export & 1211 & France & Albanie & 13559 & 12950 \\
\hline DOUANE FR 2015 & 2012 & Import & 1211 & France & Albanie & 1017297 & 520580 \\
\hline DOUANE FR 2015 & 2013 & Import & 1211 & France & Albanie & 922756 & 475952 \\
\hline DOUANE FR 2015 & 2014 & Import & 1211 & France & Albanie & 1199032 & 575686 \\
\hline
\end{tabular}

Source: Hoxha (2016)

In a national level, in this group take part the governmental institutions like the Ministry of Economy and Finance, the Ministry of Agriculture and the Ministry of Environment. The Ministry of Economy and Finance database is supplied by the Customs data (Figure 8) and the companies' activity balance sheets, which operate into the MAPs sector, (forced by the law to present their financial statements).

Figure 8

The Albanian MAPs Data from the Albanian Ministry of Economy Database

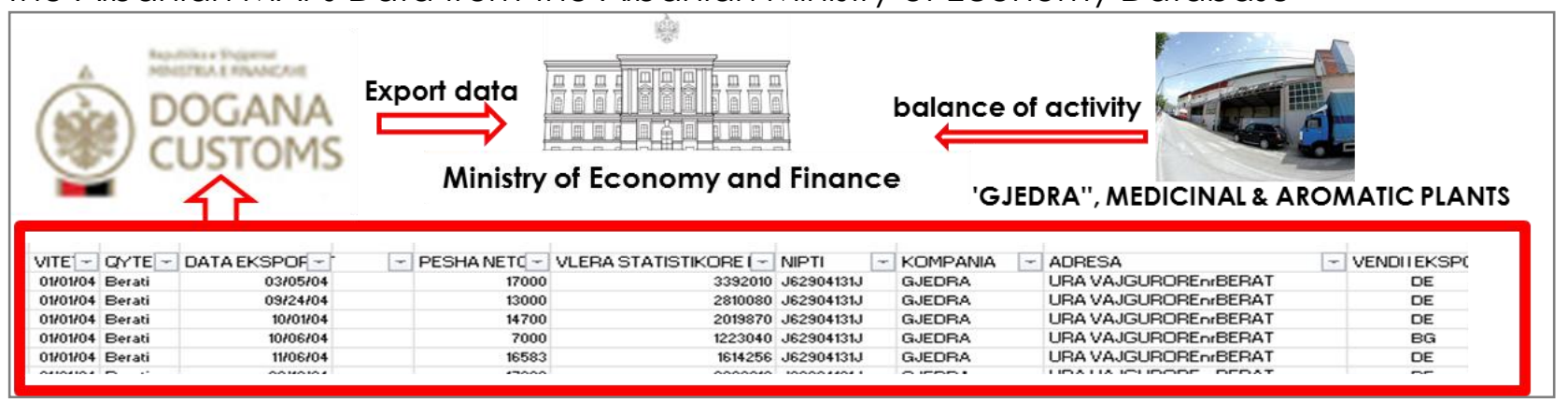

Source: Authors' illustration 
The Ministry of Environment must dispose quantity data about the capacity of these sources and geographic data about the surface of their habitats. On the other side, the Ministry of Agriculture must obtain the data about the MAPs cultivated surfaces per year.

From our research, none of these two Ministries has full information, for either the spontaneous plants or the cultivated ones. The used methodologies for the inventories and these sources identification, the lack of human resources about specialists and financial sources complicates their job. In the value chain actors' level, those who dispose data about the plants are the business-registered companies that have a regular activity. Such as collectors, processors, retailers of domestic markets and exporters (figure 5). From the realized interviews comes in evidence the difference between the export figures that are officially published from the Ministries, INSTAT and the exporters' data. The head of MAPs association, Mr. Filip Gjoka publicly declared that the MAPs exports reached about 45 million USD where from COMTRADE or Ministries statistics during the last years we have an average of about 25 million USD. Regarding the harvesters and MAPs culture cultivators, there does not exist any correct information, while their activity is not registered.

To improve this system information there is the second group of actors, which are divided according their aim of foundation. Therefore, in an international level we have the development agencies of developed countries such as USAID, GIZ, etc., the researching institutions like Universities and the researching centres in this field, those of protection and plant trafficking, where in an international level we have UICN, WWF, TRAFFIC, and others.

Usually the information found from COMTRADE and EUROSTAT is also found from FAO database, but this institution contributes also through several projects and programmes for the inventories methods improvement and the protection of these plants, cooperating with all the governmental, the researching and nongovernmental actors (NGO) (Naka et al., 2003).

In a national level, the most important ones are the universities' researching centres like Agriculture University of Tirana or University of Tirana, half public organizations like MADA (Mountain Area Development Agency), or different nongovernmental organizations where we can mention the MAPs association or EPCA (Essence Producers and Cultivators Association).

\section{Discussion}

Our research revealed that the information system identification through a 360 grades specter about the MAPs value chain in Albania is very difficult. This happens because of the sector nature, where in many cases, mostly for the processing and those of import-export companies, the information is considered an industrial secret (llbert et al., 2016). In the proposed scheme (Figure 5), we tried to put the main actors that inform or take part into the value chain identification and improvement. However, with no doubt there will remain also other ones that contribute in this network like the geomatics researchers (Hoxha, 2016), or the natural resources management which is linked in an indirect way with these sources. Possibly, this is also one of our researching limits. Even, state institutions like Ministry of Economy and Finance or the Ministry of Agriculture have a very important role for this value chain information system. The technique and legal instruments that they dispose can give more transparence, something that would help better the actors toward an efficient decision. In fact, this will remain part of an opened discussion. 


\section{Conclusion}

The lack of information for the MAPs value chain in Albania has been relieved since 2010 from USAID (USAID, 2010) and it has been identified by other studies (Hoxha, 2016, Lekocaj et al., 2017). This problem hosted our researching question about the way that the information system works and which are its creation sources.

In our results, we identified two types of actors that give and help to create the information. In the first group, there are the actors who dispose factual data from the harvesting up to the final sale. In addition, here take part all the companies that have a legal business and register everything on their balance sheets, while the state institutions control and verify their activity. Second group included the actors that contribute in an indirect way about the methods' improvement, their recognition instruments, the protection and the evaluation of these sources.

We arrived at the conclusion that in the first group of actors there exist a lack of information from the spontaneous plants harvesters and from the cultivators (about the quantity and the geographic surface identification). Even from the other actors we do not have full information regarding the statistics data, neither from the small collectors nor from the sellers in the local or foreign market.

Our recommendations always go to the creation of a monitoring system database in time and space for the entire MAPs sector, as outlined in Figure5. Thus, it is crucial the utilization of the new methods to identify the used habitats, to identify the involved actors, as well as a clear panorama of the value chain between the participating actors up to the final sale. This would directly contribute to the market transparency and on more rational decision-making by the actors who manage, use and trade these resources, while giving them the opportunity to go toward the qualitative products.

\section{References}

1. Hoxha, V. (2016), "Chapter La dynamique des plantes aromatiques et médicinales en Albanie", in Ibert H., Hoxha V., Sahi L., Courivaud A., Chailan C. (Eds.), Le marché des plantes aromatiques et médicinales: analyse des tendances du marché mondial et des stratégies économiques en Albanie et en Algérie, Montpellier: CIHEAM/FranceAgriMer, Options Méditerranéennes: Série B, Etudes et Recherches 73; 2016: pp. 45-98.

2. Ilbert, H., Hoxha, V. (2016), "Chapter Marché mondial des plantes : analyse des échanges et de la position de l'Albanie et de l'Algérie", in Ilbert H., Hoxha V., Sahi L., Courivaud A., Chailan C. (Eds.), Le marché des plantes aromatiques et médicinales: analyse des tendances du marché mondial et des stratégies économiques en Albanie et en Algérie, Montpellier: CIHEAM/FranceAgriMer, Options Méditerranéennes: Série B, Etudes et Recherches 73; 2016: pp.17-40.

3. Kaplinsky, R., Morris, M. (2001), "A Handbook for Value Chain Research", Prepared for the International Developent Research Centre (IDRC), Sustainability, UNEP and UN Global Compact, pp. 4-6.

4. Lekocaj, J., Hoxha, V., Lekaj, P. (2017), The performance and the transparency of MAPs market sector in Albania. The actors' limited rationality identification based on the value chain analysis. The forth International Conference: The problems and the challenges of the Albanian society transformation toward the EU standards, 2017.

5. Lekocaj, J., Hoxha, V. (2018), "The information asymmetry versus the actors' limited rationality. MAP value chain evidence and perspective in Albania", Albanian Journal of Agriculture Sciences (AJAS) 2018, in review process.

6. Llubani, F. (1988), Study about the MAPs inventory. Tlrane: [The station of forests, plants' culture and essential oil], Document in Albanian.

7. Naka, K., Musabelliu, B. (2003), Social and Economic Relevance of NTFPs in Albania. Albanian National Forest Inventory (ANFI) Special Study, USAID project. 
8. Paul, B. V., (2014), Assessing the Medicinal and Aromatic Plants in Albania Value chain analysis, Centre for International Development, Harvard University.

9. Rothschild, M., Stiglitz, J. (1970), "Increasing risk: I. a definition", Journal of Economic Theory, Vol. 2, No. 3, pp. 225-243.

10. USAID (2010), Albania medicinal and aromatic plants: value chain assessment. Albanian agriculture competitiveness (AAC) programme, Washington: USAID.

\section{About the authors}

Julian Lekocaj works as manager at GFI- Albania Ltd. He is graduated at the Agricultural University of Tirana where he got the Msc degree with the topic "The risk of liquidity for the second level banks in Albania". He is a PhD student candidate and his research activity is focused on the aromatic and medicinal plants value chain, by identifying and analyzing all the involved actors between the links of MAP's industry. The author can be contacted at julianlekocaj@gmail.com.

Valter Hoxha works as professor at the UMT University. He is graduated at Paul-Valéry Institution / UM3 University, Montpellier, France, where he got his PhD with the topic "An alternative methodology based on gatherers and GPS sensors to a sustainable management of the aromatic and medicinal plants". His research activity is focused on natural resources management and more specifically in the aromatic and medicinal plants using GPS technology in their identification and evaluation; territorial management and information economy. The author can be contacted at valter.hoxha@umsh.edu.al. 